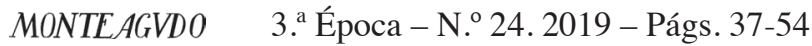

\title{
Notas SObRe LA bUENA LETRA, NOVELA CORTA PRECURSORA DE LA NARRATIVA DE LA ESPECULACIÓN INMOBILIARIA, DEL NEGO- CIO DE LAS RECALIFICACIONES FRAUDULENTAS Y DEL ESTALLIDO DE LA AUSTERIDAD Y DE LA CRISIS CREDITICIA
}

\author{
José Manuel LóPeZ de AbiadA \\ Universidad de Berna
}

\section{RESUMEN:}

El presente trabajo versa sobre La buena letra (1992), primera entrega de Rafael Chirbes del conocido díptico que concluye con Los disparos del cazador. En esta ocasión centro mi análisis en la primera obra, porque con ella se adelanta el autor en más de una década a los títulos mayores del corpus de las llamadas narraciones de la crisis financiera y social. Un conjunto de textos en el que a día de hoy las máximas aportaciones (polifónicas y desoladoras) son Crematorio (2007) y En la orilla (2013). En la primera obra del díptico, Ana, protagonista ya anciana, enhebra y zurce un largo relato dirigido a su hijo con jirones de su propia vida, desde la preguerra a comienzos de los años 90. Lo hace urgida por el deseo del hijo de vender la casa familiar para construir sobre el solar pisos al socaire del boom inmobiliario en tiempos de dinero rápido.

\section{PALABRAS CLAVE:}

Las dos Españas, corrupción, transición, traición, burbuja inmobiliaria, novela de la crisis, mentira, dinero rápido, posmodernidad.

\begin{abstract}
:
Il presente lavoro verte su La buena letra (1992), prima parte della dilogia di Rafael Chirbes che si conclude con Los disparos del cazador e che anticipa di ben oltre un decennio alcuni dei grandi titoli del corpus della cosiddetta narrativa della crisi finanziaria e sociale. Un insieme di testi i cui a tutt'oggi maggiori contributi (polifonici e desolanti) restano Crematorio (2007) e En la orilla (2013). Nel romanzo che qui si analizza, l'ormai anziana protagonista Ana intesse, con frammenti della sua vita dall'anteguerra agli inizi degli anni novanta, un lungo racconto destinato al figlio intenzionato -sull'onda del boom immobiliare in tempi di denaro facile- a vendere la proprietà familiare per costruire al suo posto degli appartamenti.
\end{abstract}

\section{PAROLE CHIAVE:}

Neoliberalismo, le due Spagne, corruzione, transizione, tradimento, bolla immobiliare, narrativa della crisi, menzogna, denaro facile, postmodernità.. 
La buena letra es un libro que aparece en el año 1992, cuando estaba de moda ser moderno y hacer dinero, teníamos la Expo y las Olimpíadas y la literatura que miraba hacia atrás estaba obsoleta. [...] lo resuelvo con una madre anciana cuyos hijos quieren vender sus terrenos para construir. A partir de ahí surgen las contradicciones porque todo lo material tiene un soporte ideológico [...] cuando se tira una casa para construir otra se destruye una parte fundamental de la memoria, la de los perdedores de la guerra en el caso de la novela.

Rafael Chirbes, «Los libros siempre saben más que su autor», Entrevista de Santiago Fernández Patón, 2014

Vivimos una época en que los embaucadores nos rodean por todas partes y la inmensa mayoría de ellos — banqueros, autoridades, dirigentes políticos y sindicales, jueces, académicos - miente y delinque para enriquecerse, sórdido designio vital, sin que sus historias trasciendan las previsibles trapacerías del ratero vulgar. Mario Vargas Llosa, «La era de los impostores», El País, 14 de diciembre de 2014.

Casi dos décadas antes del estallido de la burbuja inmobiliaria, Rafael Chirbes la vislumbró en La buena letra (1992), primera de las nouvelles del díptico que concluiría dos años después. De más está decir que esta primera entrega no podía estar tan nítidamente configurada como las novelas posteriores, especialmente Crematorio o En la orilla ${ }^{1}$, referentes máximos en la literatura española de la crisis social, ética, económica y del «sistema» inmobiliario ${ }^{2}$, acompañados de otros aspectos y te-

\footnotetext{
${ }^{1}$ Quizá viene al caso rememorar que Crematorio (2007) versa sobre la especulación inmobiliaria y urbanística, y que la obra fue galardonada con el Premio Nacional de la Crítica y el V Premio Dulce Chacón. En la orilla (2013) entra de lleno en la crisis, desatada por el estallido de la burbuja inmobiliaria. Esta novela recibió asimismo el Premio Nacional de la Crítica 2014 y otros galardones, entre los que figura el Premio Francisco Umbral.

${ }^{2}$ En la última década han aparecido ensayos notables, entre los que destacan los libros de Antonio Muñoz Molina, Lucía Etxebarría, Enric Juliana y el volumen colectivo editado por Mecke, Junkerjürgen y Pöppel, cuyas referencias figuran en la bibliografía. En cuanto a la filmografía, véase el dossier coordinado por Esther Gimeno Ugalde y Marta Álvarez en la revista Iberoamericana.

Dieter Ingenschay ha publicado un estudio bien argumentado sobre la «crisis y sus narraciones», del que procede el párrafo que sigue: «Una lista -incompleta, por cierto- podría incluir: Rafael Chirbes, Crematorio y En la orilla; Alberto Olmos, Ejército enemigo; Pablo Gutiérrez, Democracia; Isaac Rosa, La habitación oscura; Eduardo Mendoza, El enredo de la bolsa y la vida; Javier López Menacho, Yo, precario; Benjamín Prado, Ajuste de cuentas; Lucía Etxebarría, Liquidación por derribo; Esther Guillem, Bestseller; Cristina Fallarás, A la puta calle; Jesús Carrasco, Intemperie; Almudena Grandes, Los besos en el pan.» (Cfr. «Ecos de la crisis financiera y social en las literaturas hispá-
} 
Notas sobre La buena letra, novela corta precursora de la narrativa...

mas capitales, entre los que destacaba el de la corrupción. En La buena letra abunda el término casa a lo largo de la novela. En la última unidad narrativa o fragmento de cierre aparece dos veces en la misma línea el vocablo solar:

Tu prima trajo un ramo de rosas y me besó, encantadora. Fue la primera en proponerme lo que volvisteis a pedirme ayer, que deje la casa. Vosotros os encargaréis de levantar en su lugar un edificio de viviendas en el que tendré un piso cómodo y moderno, además de unas rentas. «Le quedará un buen pellizco, tía», me dijo tu prima, «y es que es una pena que esté tan desaprovechado ese solar. Me dolió que hablase de mi casa como de un solar. Vosotros volvisteis a repetirme ayer poco más o menos las mismas palabras, lo que me dio pie a pensar que lleváis bastante tiempo discutiendo el proyecto a mis espaldas. «Pero si es por usted, tía, por su tranquilidad» me había dicho tu prima. Y ayer volvisteis a repetírmelo tu mujer y tú. «Mamá, si es por tu bien», dijiste. Aún no sé cómo conseguí no echarme a llorar ni echaros de casa. (págs. 136-137)

El pasaje citado da pie a variadas interpretaciones, incluida una entonces poco frecuente en España, hoy conocida bajo la figura jurídica de «Socimi» o sociedad de inversión inmobiliaria, que entretanto cotiza en $\mathrm{Bolsa}^{3}$.

Lo que revela el pasaje citado de la novela era a finales de los años ochenta una práctica que crecía a ojos vista, que desembocaría, primero, en la Ley del suelo de 1990 (el texto fue refundido en 1992), de 1994 (con medidas liberalizadoras) y de 1998 (derogada en parte porque invadía ciertas competencias de las Comunidades Autónomas y de los Ayuntamientos). Alcanzó máximos en los últimos años de la burbuja inmobiliaria previos a la crisis de 2008 , precedida y potenciada por la paulatina quiebra del sistema de los subprimes y de las desregularizaciones de los mercados norteamericanos, que medraron durante la presidencia de Ronald Reagan por la decidida defensa de la liberación de la economía, de la especulación y de la puesta en circulación de hipotecas subprime en Estados Unidos. Lo demás es conocido: la crisis financiera y bursátil a escala mundial, la quiebra del banco de inversión

nicas actuales», en http://www.hispanistes.fr/images/PDF/HispanismeS/Hispanismes_9/3_INGENSCHAY_Dieter_HispanismeS_9.pdf.)

${ }^{3}$ La adquisición de vivienda a personas mayores es una práctica que se ha ido desarrollando como modelo de negocio de las socimis, cuya base es la adquisición de casas, viviendas o pisos a personas mayores para alquilárselos hasta su fallecimiento. Los inversores adquieren el piso o la casa a un precio inferior al del mercado, bajo la condición de que el exdueño pueda seguir viviendo en su antiguo inmueble o en uno de los pisos en derecho a vivir vita natural durante en uno de los pisos nuevos que se construyan en el solar que ocupaba la casa. Entre tanto -y ello sí es novedoso en España- se ha creado la primera sociedad de inversión inmobiliaria especializada en ese modelo de negocio, que cotiza en Mercado Alternativo Bursátil desde hace poco tiempo. 
Lehman Brothers, las caídas históricas de las bolsas y los planes de sus rescates, así como la compra de bancos de activos financieros inmobiliarios contaminados por hipotecas basura.

Menos conocida es la conformación paulatina de la burbuja inmobiliaria, que generó una rápida subida de los precios entre 1986 y 1992 sin afectar sustancialmente el volumen de inmuebles construidos ${ }^{4}$. Son los años en los que Ana, la protagonista de La buena letra, ve la necesidad de rememorar los momentos clave de sus vivencias y de su desacuerdo con la venta del «solar». El propio Chirbes me reveló en Berna (tras la presentación de la traducción alemana de La buena letra) que, a su juicio, la formación de esa primera burbuja era fruto del Decreto ley aprobado el 30 de abril de 1985, más conocido por el nombre de Ley Boyer ${ }^{5}$. También me sugirió que consultara un artículo de Isabel Vilallonga, portavoz de Izquierda Unida en la Asamblea de Madrid, publicado en El País. En dicho artículo, la autora reclamaba la derogación del decreto Boyer, porque había «favorecido la especulación urbanística y fomentado la expulsión de 250.000 vecinos de las zonas centrales de la ciudad hacia la periferia» ${ }^{6}$. El decreto confirmaba y daba alas a la repetida afirmación de otro de los ministros socioliberales del primer gobierno de Felipe González, Carlos

\footnotetext{
${ }^{4}$ Conviene recordar que en enero de 1986 entró en vigor la ley relativa al impuesto del IVA, que entonces significaba un incremento del $12 \%$ en los precios de los inmuebles de nueva construcción. No obstante, el boom inmobiliario se mantuvo hasta 1992, si bien el crecimiento entonces era mucho menor que el que tuvo su abrupto fin en 2008, tanto en lo que se refiere a las cifras de construcción de viviendas por año como en cuanto al endeudamiento de las familias en relación con la renta bruta disponible (pasó del 34\% en 1986 al 45\% en 1992; en los últimos años de la burbuja llegó a superar el 125\%). Para mayor información, véase el documentado trabajo de Sandra López Letón, El País, en https://elpais.com/economia/2015/10/20/actualidad/1445359564_057964.html.

${ }^{5}$ En su «Introducción» (subtitulada «La estrategia del Boomerang») a la colección de ensayos reunidos bajo el título Por cuenta propia, Chirbes vuelve sobre el decreto ley aprobado en abril de 1985: «Al escribir La buena letra [...], me gustaba bromear diciendo que era una novela contra la ley Boyer de alquileres urbanos: lo que quería decir era que había surgido como reacción a la España que, a fines de los ochenta, enterraba precipitadamente sus señas de identidad -la España de la Exposición Internacional y los Juegos Olímpicos- y en la que se imponía un pragmatismo caracterizado con aquella frase de corte posmaoísta que pronunció Felipe González: 'gato blanco, gato negro qué más da: lo importante es que cace ratones.' [...] Yo vivía por entonces en un pequeño pueblo de Extremadura donde la pervivencia de las viejas costumbres en la vida cotidiana e incluso la propia arquitectura de la casa en que residía me traían muchas noches [...] recuerdos de la infancia: oía corretear las ratas por el tejado [...]. El país había emprendido otros rumbos y era como si lo que yo había vivido en mi primera infancia y me había ayudado a ser quien era, no hubiese existido nunca. Me dolía pensar que el tremendo aporte de sufrimiento de aquella gente había resultado inútil». (págs. 28-29).

${ }^{6}$ Isabel Vilallonga Elviro, «La necesaria derogación del 'decreto Boyer' de alquileres», El País, 18 de marzo de 1991. El artículo $8^{\circ}$ del decreto establecía la posibilidad de transformar las viviendas en locales de negocio: «Los propietarios de fincas urbanas, los arrendatarios de estas, con el consenti-
} 
Notas sobre La buena letra, novela corta precursora de la narrativa...

Solchaga: «España es el país del mundo donde más rápido puede uno hacerse rico». Este mismo ministro terminó poniendo su biografía profesional en sintonía con el enunciado de su afirmación, fue el político que en los primeros años de los Ejecutivos de González planificó y efectuó la llamada «reconversión industrial», desmantelando o vendiendo la industria pública española a empresarios extranjeros; para ello no dudó en poner en la calle a decenas de miles de obreros. Por si no bastara, para cumplir con las exigencias del guión europeo, se liquidó buena parte del complejo industrial español. También es conocido que asumió, durante su permanencia en los Ministerios de los que fue titular, el papel de promotor y alentador de las teorías y prácticas neoliberales ${ }^{7}$.

Entre los argumentos de la citada portavoz sobre la necesidad de derogar el decreto destacaba el de la importancia de la municipalización del suelo edificable: «en los países europeos de nuestro entorno los avances sociales en materia de vivienda y calidad de vida han sido la consecuencia de un fuerte intervencionismo en materia de suelo y vivienda, que ha llevado en su mayor parte a la municipalización del suelo urbano». De ahí que considerase que la transformación de vivienda de uso residencial en locales de negocio «no ha sido un elemento importante a la hora de favorecer la especulación urbanística a cargo de las grandes inmobiliarias» ${ }^{8}$.

El decreto de marras abrió las puertas a la especulación inmobiliaria y urbanística, en la que confluían -dicho sea en palabras de Chirbes- los «arribistas de ambos

miento de aquéllos, podrán realizar libremente la transformación de viviendas [o fincas urbanas] en locales de negocio, salvo disposición contraria».

${ }^{7}$ Al presidente Rodríguez Zapatero debemos asimismo frases «memorables» referidas a la crisis, asunto que aquí nos concierne. Una de las más conocidas («España tiene el sistema financiero más sólido de la comunidad internacional») da título a un artículo de Israel Viana aparecido en la sección de Economía del diario $A B C$. Entresaco un pasaje de la extensa información sobre el debate parlamentario del 24 de septiembre de 2008: «Zapatero defendía en Nueva York, ante directivos de multinacionales y de bancos de inversión norteamericanos, la solidez del sistema español. «Quizá España tenga el sistema financiero más sólido de la comunidad internacional. Ha tenido un marco de regulación y supervisión reconocido internacionalmente por su calidad y por su rigor». En otras declaraciones, Zapatero insistió en la firmeza del sistema financiero español: «un sistema financiero sólido, muy sólido, comparable al más sólido de las economías desarrolladas». En otra circunstancia dijo: «no se trata de presumir, sino de decir lo que tenemos». Sin embargo, «tres meses antes, había utilizado por primera vez la palabra «crisis» para referirse a la situación económica del país».

${ }^{8}$ En otro pasaje del artículo leemos: «Si analizamos las razones por las que se establecía la liberalización de alquileres, veremos que dicha medida ha sido un factor complementario de la anterior ya que, en primer lugar, ha propiciado una subida en la media de los alquileres de entre $80 \%$ o $90 \%$. Entre 1985 y 1989, el número total de viviendas en nuestro país aumentó en 1.138 .556 viviendas nuevas, mientras el número de viviendas puestas en alquiler descendió en 379.164 en las mismas fechas». 
bandos» ${ }^{9}$, que se repartían «el poder de la nueva España», con el agravante de no acusar «la difusa sensación de culpa que marcaba a la vieja capa dominante engordada a la sombra de la dictadura» (pág. 29). Huelga señalar que el salto de la especulación inmobiliaria al negocio de las recalificaciones abusivas y a la corrupción sistémica era cuestión de tiempo, tenida cuenta de que la venalidad política era fruto de las deficiencias en los controles de las regulaciones urbanísticas, sobre todo en las administraciones autonómicas y locales. La liberalización del suelo edificable de 1996, la creación del euro y la cuantía de créditos asequibles y a veces depreciados dieron fuerza a las economías locales y facilitaron el acceso a los delitos ${ }^{10}$.

En ese caldo de cultivo nacen las aspiraciones y el cometido capital del escritor valenciano: «crear un fondo literario en el que poner a salvo -o almacenar- parte de aquel dolor de mis padres, recobrar la narración de su esfuerzo como unidad de medida desde la que calibrar la falaz levedad de los nuevos tiempos que nos tocaba vivir, para todo ello no encontré otro camino que no fuese el de devolver la literatura al entramado de la historia» ${ }^{11}$ (pág. 32). Y «entramado de la historia» quiere decir para Chirbes «lieux de mémoire», lugares de memoria en el sentido de Pierre Nora, inmunes a las modas y al paso del tiempo. Y por la «falaz levedad de los nuevos tiempos» entiende «la necesidad de saber moverse entre la seducción de los lenguajes», que en la novela que analizamos (y en palabras de la protagonista) significa que «la buena letra» corresponde al «disfraz de las mentiras» (pág. 13) ${ }^{12}$.

En Los disparos del cazador -y desde la «falacia» del protagonista- Chirbes señala que Carlos Císcar «acaba desnudando los valores de la nueva clase» (pág. 33), entre los que figuran carencias y deficiencias en la cultura cívica que manaba del turbio venero de la dictadura franquista. Sin embargo, cuando Chirbes escribe las dos obras que conforman el díptico, haz y envés de un mismo tiempo y una misma realidad política (los dos últimos gobiernos de Felipe González), los vínculos entre corrupción y sistema democrático eran para nuestro novelista claramente perceptibles, presen-

\footnotetext{
${ }^{9}$ Es el caso de los descendientes del protagonista de Los disparos del cazador (1994), la segunda nouvelle del díptico, que trataré en otro trabajo.

${ }^{10}$ Para una información sucinta, fehaciente y sopesada sobre estos asuntos, véase el excelente estudio introductorio de Fernando Vallespín al libro póstumo de Javier Pradera Corrupción y política. Los costes de la democracia, Barcelona, Galaxia Gutenberg, 2014, págs. I-XXX.

${ }^{11}$ Todas las citas últimas proceden del ensayo introductorio a Por cuenta propia. Leer y escribir, titulado, como queda dicho, «Introducción: la estrategia del boomerang», Barcelona, Anagrama, 2010.

${ }^{12}$ Cito siempre por la tercera edición de la Editorial Debate, marzo 2000 (La buena letra es el disfraz de las mentiras).
} 
Notas sobre La buena letra, novela corta precursora de la narrativa...

taban aspectos y adquirían características «sistémicas», pese a que en aquellos años España ya era considerada en el grupo de países con mayor calidad democráticas ${ }^{13}$.

En la nota del autor a la edición aparecida en la Editorial Debate (en esta edición suprime la última unidad narrativa de las 56 que componían la novela, en la que «las dos cuñadas -Ana e Isabel- volvían a encontrarse tantos años después», pág. 7), leemos lo que sigue:

Si cuando escribí La buena letra no acababa de sentirme cómodo con esa idea de justicia del tiempo que parecía surgir del libro, hoy, diez años más tarde, me parece una filosofía inaceptable por engañosa. El paso de una nueva década ha venido a cerciorarme de que no es misión del tiempo corregir injusticias, sino más bien hacerlas más profundas. Por eso, quiero librar al lector de la falacia de esa esperanza y dejarlo compartiendo con la protagonista Ana su propia rebeldía y desesperación, que al cabo son también las del autor. (pág. 8)

En una de sus últimas entrevistas, aparecida en la revista Ínsula en 2013, vuelve a opinar sobre la traición de la transición, la supuesta riqueza de España («un espejismo montado desde Europa») y sobre quienes han aceptado la transición y la defienden, que, a su juicio, son «perdedores que han conseguido un poquito de poder»; «un poquito» porque a juicio del escritor era la «clase alta» la que iba a «dirigir la transición, es decir, los herederos, los hijos de Los disparos del cazador, que son los Pradera, los Ferlosio [...]. La continuidad legitimada por su militancia antifranquista, con lo cual no han tenido que pedir perdón ni disculpas $[\ldots]^{1{ }^{14}}$

Y cuando me dicen que La buena letra es un libro de posguerra, pues no señor, es un libro del 92, publicado en el 92 y que habla del 92. Fíjate que «vamos a tirar la casa para hacer un solar en el que vamos a construir apartamentos» es el final de la novela. Y Los disparos del cazador es también el 92, «Estamos haciendo muchas obras públicas». «Estaréis ganando mucha pasta». «Papá, no seas basto. Son obras sociales». ${ }^{15}$

\footnotetext{
${ }^{13}$ En el ranking de Transparencia Internacional del año 2000, España ocupaba el puesto 20 de un conjunto de 176 países. En 2013, ya ocupaba el puesto 40. En el ranking del Economist Democracy Unit relativo a la calidad de la democracia de los países en 2008, España ocupaba el puesto número 15, por delante de Francia, Reino Unido, Estados Unidos o Italia. Cuatro años después, ocupaba el puesto 25. Más información en el estudio introductorio indicado de Fernando Vallespín, págs. III-IV.

${ }^{14}$ Tanto las citas de este párrafo como las dos que siguen proceden de la entrevista a Rafael Chirbes realizada por Teresa Barjau y Joaquim Parellada, Ínsula, núm. 803, 2013.

${ }^{15}$ Barjau y Parellada, «Rafael Chirbes en Beniarbeige», cit., pág. 20.
} 
Como en varias otras ocasiones, Chirbes vuelve a subrayar en esta entrevista que la temporalización de sus novelas suele focalizar los momentos respectivos de la transición para relatar lo que a su entender fue una traición y que por ello con frecuencia va a contrapelo de las versiones «canónicas» de la «historia oficial», a la que opone los relatos «particulares» de los personajes de sus novelas:

Fíjate que Mimoun es el perdedor de la transición y es una novela que mira a África cuando España mira a Europa, una novela que ofrece miseria cuando Europa ofrece bienestar y que habla de la imposibilidad de un paraíso fuera de la historia. Entonces te vuelves a la historia, que es lo que hace el personaje. En la lucha final sale de que estoy viendo a todos mis amigos colocarse como fieras. En realidad es Roldán ${ }^{16}$ y sus muchachos [...], al que todo el mundo quiere. [...]. La buena letra sale de que, de repente, es la Expo de Sevilla, la Olimpiada de Barcelona, la movida de Madrid y yo digo «todo esto, lo que han pasado mi madre, mi abuela, mi padre, todo eso ha volado, ha desaparecido, ya no va a existir». $\mathrm{Y}$ es la necesidad de que exista.

Chirbes era en 1990 probablemente uno de los pocos novelistas que ya denunciaba en sus obras aspectos de la transición, en la que pocos percibían advertencias o amenazas posibles. En el fondo, eran pocos los escritores que se percataban del peligro, pocos los políticos y también pocos los economistas. Lo confirma y denuncia con la autoridad que le caracteriza Muñoz Molina en su imprescindible ensayo Todo lo que era sólido:

Como tanta gente en España, yo también estaba enfermo de pasado, contagiado del mismo delirio que me desconcertaba en los demás. Para escribir una novela [alude a El jinete polaco y a otros títulos] leía con más atención los periódicos de 1936 que los de 2007. [...] Yo escribía sobre la ceguera de quienes no saben ver lo que está ocurriendo en medio de la agitación del presente [...], por la pura inercia de creer que las cosas son mucho más sólidas de lo que en realidad son. Pero yo tampoco veía nada, absorto en mi escritura, encerrado en 2007 en mi cápsula del tiempo de $1936 .{ }^{17}$

\footnotetext{
${ }^{16}$ Chirbes se refiere al enigma del «caso Roldán». Luis Roldán fue nombrado en 1986 por el Gobierno de González director de la Guardia Civil. Ocho años después se fugó de España tras ser destituido. Su patrimonio rondaba entonces los 400 millones de pesetas; el escándalo generó a juicio del juez Baltasar Garzón una «sensación de desgobierno y corrupción» (pág. 111). Para mayor información, véase las páginas 109-116 del libro de Garzón, cuyas referencias figuran en la bibliografía.

${ }^{17}$ Antonio Muñoz Molina, Todo lo que era sólido, Barcelona, Seix Barral, 2013, págs. 150-151.
} 
Notas sobre La buena letra, novela corta precursora de la narrativa...

La afirmación categórica de Ana antes citada («La buena letra es el disfraz de las mentiras») coincide en su significado con las múltiples críticas que Chirbes dirige a los políticos que pilotaron la transición. Son críticas a los relatos del pasado posbélico y a los discursos sobre la bonanza de los primeros años de la etapa posfranquista; y a la aceptación del relato que consideraba que la guerra civil había sido una tragedia colectiva en la que habían participado las «dos Españas». Chirbes criticaba duramente a quienes consideraban que en la transición se había superado el peligro del conflicto armado y que la transición había sido el mejor medio posible para progresar y entrar por fin en la «modernidad». En La buena letra, contrapone a ese discurso de participación de las «dos Españas» la «rebeldía» y la «desesperación» del relato de Ana, que, como asegura al final la nota a la edición del año 2000, esa rebeldía y esa desesperación, al cabo, «son también las del autor» (pág. 8).

Esta afirmación nos lleva a corroborar que la protagonista de La buena letra es el personaje de su creación novelesca que Chirbes siente más cercano a sus propias vivencias de infancia y juventud. Vivencias que después irían conformando sus convicciones políticas, sociales y literarias; y también su visión del mundo. Nos lo confirman otros pasajes de la «Nota del autor», en los que da fe de la supresión del fragmento -o, quizá mejor, unidad narrativa (el autor lo denomina «capítulo»)- final de la novela. Escribe que lo hacía por mor de devolver al lector al «presente narrativo del que lo había hecho partir», animado por cierto «voluntarismo literario en tal propósito» y por «cierto criterio de circularidad». Casi una década después optaba sin embargo, como hemos visto, por la eliminación del fragmento, dado que, a su juicio, en «ese final había cometido un error de sintaxis narrativa», tanto «más grave aún por la filosofía que venía a expresar, y que no era otra que la de que el tiempo acaba ejerciendo cierta forma de justicia, [...] poniendo las cosas en su sitio». Lo corregía porque deseaba «librar al lector de la falacia de esa esperanza y dejarlo compartiendo con la protagonista Ana su propia rebeldía y desesperación», que eran también las propias.

La supresión del último fragmento refuerza el significado del cierre de la novela, y muy especialmente de la última frase, que consta de dos solas palabras, «Ahora, espero». Mas ¿qué puede esperar Ana, si las decisiones de su hijo y de su sobrina no eran otras que edificar pisos sobre el «solar» que ocupa la casa? Su casa de casi una vida, que para Ana era unidad de espacio y tiempo, cronotopo indisoluble en el que había vivido y recordado tantas veces episodios de la vida de los seres queridos y los momentos (tristes o alegres) memorables de tantas vidas.

¿Qué había observado el autor en los casi diez años que transcurren entre la fecha en la que concluye la novela («Denia, agosto, 1991») y el año de la tercera edición, en la que da fe del cambio que ha llevado a cabo mediante la eliminación del último 
fragmento? Lo más claramente perceptible para el escritor valenciano era el devenir de la transición, tan presente en la mayoría de sus novelas y en sus conferencias y entrevistas (muchas de ellas recogidas en sus ensayos). Un devenir que le impuso el recurso a una ecuación fundida en una casi paronomasia para definir la equivalencia: transición igual a traición. Por lo demás, la primera de esas fechas coincide con el tercer mandato de Felipe González. En la segunda, José María Aznar se hallaba en el cénit de su segundo gobierno, aunque sin todavía barruntar cuál sería el desenlace ${ }^{18}$.

Viene al caso rememorar una entrevista de Javier Rodríguez Marcos (crítico, editor y periodista de renombre, amén de amigo del escritor desde los años estudiantiles en la Facultad de Filosofía y Letras de la Universidad Complutense). En esa larga conversación, el periodista pregunta al escritor por las razones que le habían llevado a afirmar tantas veces que concebía la «transición como una larga traición». Chirbes responde como sigue:

Es lo que descubre Max Aub en los sesenta, no hay dos Españas, sólo hay una, la otra no existe. Toda aquella enseñanza de la Institución Libre y los ateneos obreros no nos había llegado. Habían llegado tres poemas de Alberti, pero no esa manera de ver el mundo que no era el crucifijo y el Cara al sol en las escuelas. Aunque recordar esto es crear un problema porque se supone que hemos llegado a un acuerdo y ahora debemos llevarnos civilizadamente. Pero el que ocupó las tierras se quedó con las tierras ocupadas y el que ocupó la cátedra con la camisa azul se quedó con ella. Hubo un pacto para no matarse, pero hay que saber que alguien había perdido.

Cuando el entrevistador desea saber las razones de la pérdida de «esa memoria», el escritor responde:

\footnotetext{
${ }^{18}$ Aludo a las consecuencias de la «gran mentira» fraguada y cultivada contra el honor y la impecable profesionalidad del comisario y jefe de los Tedax (Unidad de desactivación de explosivos), Juan Jesús Sánchez Manzano. Una «gran mentira» por estar relacionada con los atentados del yihadismo del 11 de marzo de 2004. Entre la inmensa información sobre la autoría del atentado, la entrevista publicada por El País recientemente es la más concisa, con el añadido de que la respuesta es del comisario directamente concernido. A la pregunta de la periodista sobre cómo, cuándo, dónde y a qué razones se debía la calumnia, Sánchez Manzano responde: «Según publicaron posteriormente los medios de comunicación, fue en Moncloa. El 11 de marzo era jueves y el domingo había elecciones generales. Al parecer, uno de los asesores del presidente Aznar le dijo: «Si ha sido ETA barremos, pero si son los yihadistas ganará el PSOE». A partir de que en Moncloa se hablara en esos términos, empiezan los comunicados adjudicando la autoría a ETA». Más información en «Juan Jesús Sánchez Manzano, Comisario y Jefe de los Tedax en el 11-M, "El Gobierno de Aznar me pidió que asumiera su mentira sobre el 11-M"», El País, 11 de marzo de 2019, entrevista realizada por Patricia Ortega Dolz, en https:// "El+gobierno+Aznar+me+pidio+que+asumiera+su+mentira\&rlz=1C1GCEA_enCH800CH8 00\&oq=orte\&aqs=chrome. $0.69 \mathrm{i} 59 \mathrm{j} 69 \mathrm{i} 57 \mathrm{j} 014.8546 \mathrm{j} 0 \mathrm{j} 4 \&$ sourceid $=$ chrome \&ie=UTF- 8 .
} 
Notas sobre La buena letra, novela corta precursora de la narrativa...

El PSOE se quería ganar a las clases medias provenientes del franquismo, y esa memoria no le servía para nada... hasta que pierde las elecciones. Cuando se descubre que el vaso natural de la otra memoria es el PP, se quedan sin referentes porque, como decía [Walter] Benjamin, la memoria es la apropiación de un hecho pasado. «¿Y ahora? », se dicen. Y empieza la eclosión de la novela de la guerra. Surge el problema de la legitimidad.

Y a la pregunta «¿En qué consiste?», el escritor responde:

La cuestión es, ¿usted de quién procede?, ¿en nombre de quién ostenta el poder? Aznar afirma proceder de ese liberalismo que dice, «En la guerra se mataron los rojos y los azules. Yo soy el centro e inauguro a Max Aub y a Lorca», y la Residencia de Estudiantes se convierte en objetivo privilegiado porque se está saqueando una parte de la memoria que otros han dejado saquear. Los socialistas se lo hubieran impedido uniéndola a su carro triunfal, pero no lo hicieron. ${ }^{19}$

El lector experimentado se percata pronto de que el discurso de Ana es el de la verdad; es un monólogo hablado en primera persona, en el que se trasluce el modo de entender y argumentar del autor, como se puede observar en algunos de los textos recogidos en sus ensayos. Actúa, por tanto, cual instancia narrativa en la sombra y va guiando el discurso de Ana. Se trata de la misma instancia narrativa que en el texto previo al corpus novelesco del año 2000, en el que afirma, recurriendo a la captatio benevolentiae, que «había cometido un error de sintaxis narrativa», o, lo que es lo mismo, que no había acertado siempre en la distribución y el orden de las acciones y en la configuración de algunos de los personajes ${ }^{20}$.

La obra de Rafael Chirbes se caracteriza por una preocupación temática y una constancia en la elección de motivos literarios, tiempos históricos y momentos políticos que se desarrollan, crecen y se reflejan en realidades sociales y económicas determinadas. En su obra ensayística abundan los pasajes para comprobar y acreditar estas afirmaciones, como hemos podido apreciar en varias ocasiones. En la

\footnotetext{
${ }^{19}$ Javier Rodríguez Marcos, «Las novelas se escriben contra la literatura», El País, 21 de junio de 2003, en https://elpais.com/diario/2003/06/21/babelia/1056153015_850215.html.

${ }^{20}$ Dice bien Pozuelo Yvancos cuando observa: «Rafael Chirbes ordena de un modo muy preciso el suceder de los acontecimientos que la novela desarrolla. Lo hace en tiempos que acompasan la evolución psicológica y moral de los personajes del núcleo familiar con la evolución del país en su conjunto. Quizá la característica estilística más relevante de esta novela es que en ella (en realidad en ninguna de las de su autor) no podemos entender por separado la historia familiar y la social». (José María Pozuelo Yvancos, «La buena letra: memoria y olvido», Turia, núm. 112, noviembre 2014-febrero 2015, págs. 211-212).
} 
cita adelantada parcialmente en la nota 5 (que aquí ampliamos) sobre Valverde de Burguillos, el pueblo extremeño en el que comenzó la escritura de la novela, leemos:

Yo vivía por entonces en un pequeño pueblo de Extremadura, donde la pervivencia de las viejas costumbres en la vida cotidiana e incluso la propia arquitectura de la casa en que residía me traían muchas noches, cuando me acostaba, recuerdos de infancia, oía corretear las ratas por el tejado, olía a madera, a cañas, a campo recién humedecido por una tormenta de verano, a leña quemada; y, al cerrar los ojos, veía a mis padres, a mi abuela, a mis vecinos, todos ellos habían muerto ya, y en aquellas noches me daba por pensar que de cuanto habían sido no iba a quedar nada; nada de sus esfuerzos, de su callado heroísmo, de su casi imposible empeño por mantener la dignidad en los años difíciles de la posguerra, la represión política y el hambre. El país había emprendido otros rumbos y era como si lo que yo había vivido en mi primera infancia y me había ayudado a ser quien era, no hubiese existido nunca. Me dolía pensar que el tremendo aporte de sufrimiento de aquella gente había resultado inútil. (págs. 28-29).

El relato de Ana brota de un venero abundante y de una herida dolorosa, el miedo a perder su casa y el dolor de constatar que esa pérdida era debida a la codicia de su propio hijo y a la avidez de su sobrina. Un miedo que no se limita a la casa: abarca también los miedos ${ }^{21}$ a la pobreza, a las humillaciones, a los sufrimientos vividos tras la guerra civil debido a su condición y su pasado republicanos, a la viudez, al «recuerdo de la sombra herida» (pág. 135) de su marido, a las ratas famélicas del desván durante la guerra y demás, sabedora sin embargo de que, pese a la miseria, «aquella lucha desesperada por la supervivencia era la forma de amor que nos habían dejado» (pág. 50).

Pedro Alonso ha señalado que la casa es en La buena letra el «cronotopo por excelencia de la rememoración del pasado», y diferencia cuatro niveles: «(1) la casa como espacio animista, (2) la casa como espacio de intimidad, (3) la casa como cárcel o ausencia de libertad, y (4) la casa como espacio de la memoria de los perdedores de la guerra $»^{22}$.

Sobre el primer nivel entresaco algunos de los elementos más significativos: la fotografía del cajón del aparador (que recuerda a Ana a los seres amados fallecidos);

\footnotetext{
${ }^{21}$ Sobre el motivo del miedo, véase el trabajo de Encarnación García de León, «El miedo, legado generacional en los personajes de Chirbes», en María-Teresa Ibáñez Ehrlich (ed.), Ensayos sobre Rafael Chirbes, Madrid, Iberoamericana/Frankfurt am Main, Vervuert, 2006, págs. 31 -79.

${ }^{22}$ Alonso, Pedro, «Contra el ruido y el silencio: los espacios narrativos de la memoria de la posguerra española», en María-Teresa Ibáñez Ehrlich (ed.), Ensayos sobre Rafael Chirbes, Madrid, Iberoamericana/Frankfurt am Main, Vervuert, 2006, pág. 20.
} 
Notas sobre La buena letra, novela corta precursora de la narrativa...

el desván (que le rememora el cuento del muerto que le contaba el abuelo Juan cuando era niña, que es además el lugar donde se esconden Tomás y Paco al terminar la guerra).

Del segundo nivel o espacio de la intimidad añado uno relativo al nacimiento de los hijos de Ana, que, a juzgar por la información que tenemos, nacieron en casa. Y rememoro dos de los secretos mejor guardados: el cuaderno de dibujos de su cuñado Antonio con los retratos de Ana; el cajón cuya «parte inferior había sido forrada con una hoja de papel que el tiempo había vuelto amarillenta» (pág. 133), que Antonio separa de la madera para mostrarle a su cuñada el retrato que de ella había dibujado hacía mucho tiempo, que había «permanecido durante años oculto» (pág. 133).

Como «oculta» había permanecido la atracción silenciada que Ana sentía por Antonio, que se refugió en casa de su cuñada cuando fue puesto en libertad, donde intenta superar el trauma del encarcelamiento y la condena a muerte. Ana veía en Antonio a un «hombre asustado» que se encerraba «en su cuarto casi todo el tiempo, como si no consiguiera acostumbrarse a los espacios abiertos» (pág. 59). Mejoraba ocupándose en la talla de madera y pronto pudo hacer en la casa «un verdadero taller», sobre todo tras la incorporación de José, un muchacho de Bovra que había compartido celda con Antonio. Con el pasar del tiempo, aumentan los clientes y crecen las listas de los pedidos, más pronto Antonio comienza a ausentarse de casa, hasta que un día Ana descubre que la ropa sucia «olía a perfume de mujer». La confesión de Ana sobre el hallazgo no deja espacio a la duda: «ese olor me hizo tanto daño que tuve que inventarme una excusa para salir de casa, porque allí dentro me asfixiaba» (pág. 69).

Un hecho muy significativo por su alto valor simbólico que puede pasar desapercibido es el de las sábanas que Ana regala a su hijo y a su esposa: tenían bordados los nombres de su esposo Tomás y el suyo, pero hijo y nuera las habían puesto en el trastero y se echan a perder. Significativo porque ilustran que el sistema de valores ha cambiado, que para el hijo cuenta más la venta de la casa y la edificación del solar que los regalos de su madre. Y de alto valor simbólico es el pasaje que da fe del hallazgo del cuerpo de Tomás, por el inconfundible hipotexto kafkiano (« [...] transformado en un monstruoso insecto. Estaba echado sobre el duro caparazón de su espalda. »): «Apareció con la espalda hundida en el barro, como un insecto que hubiese caído boca arriba y el peso del caparazón no le hubiera dejado incorporarse» (pág. 122).

Pocos días después de la muerte de su hermana Gloria, Antonio se presenta «de improviso» en casa de su cuñada. No lo hace para disculparse por las traiciones y desprecios cometidos tras haber conocido a Isabel y haberse casado con ella. Regresa quizá para ver a Ana y porque en su casa había recuperado las ganas de vivir. Ana 
rememora el regreso del cuñado como sigue: «Me pidió que preparase un refresco y se quedó en silencio, con el vaso de limón entre las manos, mirándome coser. Yo pensaba que, desde esa misma silla en que cosía, lo había visto recoger sus escasas pertenencias el día en que tu padre les pidió que se marcharan de casa» (pág. 130).

Las traiciones más perceptibles están relacionadas con la ostentosa amistad de Antonio e Isabel con Raimundo Mullor (el falangista más poderoso de Misent, que además había golpeado a Tomás al terminar la guerra), su asistencia al casino y a los partidos de fútbol en la tribuna y al lado de Mullor y otros falangistas locales. Para Ana, esos y otros «recuerdos eran como los ladrillos de la casa que nos habíamos esforzado en construir y que, ahora, de repente, se desmoronaba dejándonos otra vez a la intemperie. El sufrimiento no nos había enseñado nada» (pág. 109). Cuando Ana intuye la cercanía de la muerte de Antonio no duda en sentenciar: «Supe que iba a irse pronto y que, cuando se fuera, ya no me quedaría nada de aquel pasado. Sombras» (pág. 133).

Y cuando Ana constata que su hijo coincide con su prima en considerar la casa de su madre como un solar sobre el que se podrían construir edificios de varios pisos, se percata de que su hijo se ha pasado al grupo de los vencedores, que la lucha, las humillaciones y los sufrimientos de toda su vida no habían sido suficientes para evitar la derrota. Comprende que le había faltado «esa capacidad para hablar con palabras dulces» que su cuñada Isabel tenía; que le «faltaba saber escribir en un cuaderno pequeño con letra segura y bes y eles como velas de barco empujadas por el viento»; que ahora «no era suficiente la compasión, la entrega»; que la «vida nos exigía algo más: otra cosa que no habíamos imaginado que iba a hacernos falta y que intuíamos que tenía que estar en algún lugar de nosotros mismos [...]»: que nos «faltaba el plano que nos llevase hasta ese lugar secreto. Y vagábamos perdidos sin encontrarlo» (pág. 106).

Por lo demás, como hemos podido ver en la «Nota del autor» a la edición del año 2000, también Ana «había cometido un error de sintaxis narrativa»: no había sabido llevar a cabo la «transformación» durante los años de la Transición. No había querido (o podido) «evolucionar», como había hecho la mayoría de la población española, que entre tanto había cambiado su sistema de valores y consideraba que la ecuación «transición como traición» era equivocada.

En la entrevista de Santiago Fernández Patón al novelista que figura en el epígrafe, a la afirmación «Lo cierto es que en sus libros, aun en los más aparentemente introspectivos, está muy presente su tiempo», Chirbes responde:

Es que no entiendo lo privado sin lo público ni lo público sin lo privado. En eso soy balzaquiano, con perdón de Balzac, y creo en su máxima de que «La novela es la vida privada 
Notas sobre La buena letra, novela corta precursora de la narrativa...

de las naciones». Me gusta mucho la gente e intentar ponerme en la cabeza de cada uno. Los asesinos tienen también su corazoncito, y eso no quiere decir que los quieras. Si pretendes escribir novelas, y no editoriales de periódicos, tienes que tener eso en cuenta y narrar lo privado de cada personaje: ése es el espacio de la novela y si lo pierdes se pierde la literatura. Yo no he hecho una novela de la transición, por ejemplo, he hecho una novela de personajes en la transición.

Efectivamente, La buena letra no es la novela de Ana. Es la primera entrega de un díptico narrativo en la que Rafael Chirbes da la palabra a la representante de una generación a la que la dictadura había condenado al silencio. El autor da voz a la protagonista de una ficción que el escritor pergeña desde las vivencias y los recuerdos de su infancia y de su adolescencia, enriquecidos por los saberes adquiridos durante sus años de formación de estudiante de Historia influido por el marxismo en la Universidad Complutense de Madrid, primero, y en los seminarios de Carlos Blanco Aguinaga ${ }^{23}$, después. La traición que más afecta a Ana es la de su propio hijo: Chirbes también sabía por su madre y su abuelo lo que había sido la posguerra, como relata en Mediterráneos. Esa experiencia es la que también cuenta en La buena letra, como ha declarado en numerosas entrevistas, en las que fungía de portavoz de los herederos de la derrota.

Pero además, las características genéricas de la nouvelle y los imperativos de sintaxis narrativa que llevaron al autor a suprimir el último fragmento de la obra son pruebas evidentes de que Chirbes se ha propuesto respetar los criterios y requisitos narrativos de la novela corta, tanto en la extensión y el ordenamiento de las acciones como en las interrelaciones de los personajes. Así se explica la ausencia de escenas detalladas de las transgresiones y los delitos repetidos durante la posguerra, de la violencia física de Mullor con respecto a Tomás, de la traición de Antonio (que termina conchabado con Mullor), del desarrollo del conflicto generado por Isabel al socaire de las precariedades afectivas y emocionales de su futuro marido, de la sobriedad informativa sobre los fusilamientos, ante las paredes de los cementerios, de las miserias y padecimientos de las personas en los trenes atiborrados de viajeros, etc.

\footnotetext{
${ }^{23}$ En la nota necrológica que publica en El País el 29 de septiembre de 2013 sobre su maestro leemos: « [...] la literatura pierde una de las voces críticas más importantes del siglo XX. Pero yo quiero escribir de la pérdida del maestro que me enseñó a leer, porque uno puede llegar a los veinticinco años sin parar de devorar libros y seguir acunado en esa niebla engañosa que tantas veces se nos hace creer que es la literatura. Con Blanco aprendí la literatura como forma de conocimiento: colocarse ante el puro texto, sin retórica envolvente, y aprender, de paso, que el envite no es tanto situar un libro en su contexto, sino desentrañar el modo en que el contexto forma parte de la malla del libro. La literatura, como ineludible sismógrafo (o policía) de su tiempo». En http://www.sinpermiso.info/textos/carlosblanco-aguinaga-1926-2013-el-sabio-que-me-ense-a-leer
} 
También por ello, los méritos de esta novela corta, armada con las vivencias, los recuerdos y las historias de vidas «menores» de una familia republicana, constituyen el inicio de las obras mayores de Rafael Chirbes sobre el devenir de la Transición española, considerada desde varias perspectivas de los vencidos, de los desmemoriados, de los «adaptados» al nuevo sistema de valores y de los traidores. En la otra novela corta del díptico tratará el autor de nuevo varios aspectos que en ésta no podían, por las razones que hemos vislumbrado arriba, hallar su espacio. ${ }^{24}$ La buena letra inaugura un corpus novelesco ascendiente que culmina en En la orilla, por lo que se adelanta más de una década a la narrativa de la austeridad o de la burbuja inmobiliaria.

\section{Bibliografía}

Chirbes, Rafael, La buena letra, Barcelona, Editorial Debate, 2000. , El novelista perplejo, Barcelona, Anagrama, 2002.

2010. , El viajero sedentario, ciudades, Barcelona, Anagrama, 2010 , Por cuenta propia. Leer y escribir, Barcelona, Anagrama, , «Carlos Blanco Aguinaga (1926-2013), el sabio que me enseñó a leer», en http://www.sinpermiso.info/textos/carlos-blanco-aguinaga-1926-2013-elsabio-que-me-ense-a-leer

Alonso, Pedro, «Contra el ruido y el silencio: los espacios narrativos de la memoria de la posguerra española», en María-Teresa Ibáñez Ehrlich (ed.), Ensayos sobre Rafael Chirbes, Madrid, Iberoamericana/Frankfurt am Main, Vervuert, 2006, págs. 11-29.

Barjau, Teresa y Parellada, Joaquim, «Rafael Chirbes en Beniarbeige», Ínsula, núm. 803, 2013 págs. 13-21.

Etxebarría, Lucía, Liquidación por derribo (Cómo se gestó la que está cayendo), Barcelona, Planeta, 2014.

Fernández Patón, Santiago, «Los libros siempre saben más que su autor», en https://fernandezpaton.net/2014/10/07/entrevista-con-rafael-chirbes-los-librossiempre-saben-mas-que-su-autor/.

\footnotetext{
${ }^{24}$ Para mayor información, véase nuestros ensayos sobre La larga marcha, Los viejos amigos y Crematorio, recogidos en José Manuel López de Abiada y Augusta López Bernasocchi (eds.), La constancia de un testigo. Ensayos sobre Rafael Chirbes, Madrid, Verbum, 2010.
} 
Notas sobre La buena letra, novela corta precursora de la narrativa...

García de León, Encarnación, «El miedo, legado generacional en los personajes de Chirbes», en María-Teresa Ibáñez Ehrlich (ed.), Ensayos sobre Rafael Chirbes, Madrid, Iberoamericana/Frankfurt am Main, Vervuert, 2006, págs. 31 -79.

Garzón, Baltasar, El fango. Cuarenta años de corrupción en España, Barcelona, Editorial Debate, 2015.

Gimeno Ugalde, Esther y Álvarez, Marta (coordinadoras), Dossier. Paisajes de la crisis en los cines ibéricos, Iberoamericana, núm. 69, noviembre 2018, págs. 5-102.

Ingenschay, Dieter, «Ecos de la crisis financiera y social en las literaturas hispánicas actuales», en http $/ /$ www.hispanistes.fr/images/PDF/HispanismeS/Hispanismes_9/3_ INGENSCHAY_Dieter_HispanismeS_9.pdf.

Juliana, Enric, Modesta España. Paisaje después de la austeridad, Barcelona, RBA, 2012.

López de Abiada, José Manuel y López Bernasocchi, Augusta (eds.), La constancia de un testigo. Ensayos sobre Rafael Chirbes, Madrid, Verbum, 2010.

López Letón, Sandra, «La burbuja que embriagó a España. El auge inmobiliario que nadie se atrevió a enfriar tuvo consecuencias devastadoras. », El País, https,// elpais.com/economia/2015/10/20/actualidad/1445359564_057964.html.

Mecke, Jochen, Junkerjürgen, Ralf y Pöppel, Hubert (editores), Discursos de la crisis. Respuestas de la cultura española ante nuevos desafíos, Madrid, Vervuert/ Iberoamericana, 2017, 298 págs.

Muñoz Molina, Antonio, Todo lo que era sólido, Barcelona, Seix Barral, 2013, 253 págs.

Pozuelo Yvancos, José María, «La buena letra, memoria y olvido», Turia, núm. 112, noviembre 2014-febrero 2015, págs. 208-214.

Pradera, Javier, Corrupción y política. Los costes de la democracia. Estudio introductorio de Fernando Vallespín, Barcelona, Galaxia Gutenberg, 2014.

Rodríguez Marcos, Javier, «Las novelas se escriben contra la literatura», El País, 21 de junio de 2003, en https,//elpais.com/diario/2003/06/21/babelia/ 1056153015_850215.html.

Sanchez Manzano, Juan Jesús, «El Gobierno de Aznar me pidió que asumiera su mentira sobre el 11-M», El País, 11 de marzo de 2019, entrevista realizada por Patricia Ortega Dolz, en https $/ /$ »El+gobierno+Aznar+me+pidio+que+asumiera+su + mentira\&rlz=1C1GCEA_enCH800CH800\&oq=orte\&aqs=chrome.0.69i59j69i57j 014.8546j0j4\&sourceid=chrome\&ie=UTF-8 .

Viana, Israel, «Zapatero, "España tiene el sistema financiero más sólido de la comunidad internacional"», $A B C$, https,//www.abc.es/20120612/economia/abci-zapaterosistema-financiero-201206121309.html. 
José Manuel LóPEZ de AbiadA

Vilallonga Elviro, Isabel, «La necesaria derogación del 'decreto Boyer' de alquileres», El País, 18 de marzo de 1991, en https,//elpais.com/diario/1991/03/18/ madrid/669299063_850215.html. 